\title{
Evocación del Viejo Colegio
}

\section{Rdo. Padre Rector:}

Reverendos Padres:

Señoras: Señores:

QIGUIENDo la pauta que da la tónica espiritual a la Com$D$ pañía de Jesús desde los años mismos de su fundación, el cuarto centenario de este suceso de resonancia universal se celebra en Cuba, en la Habana, con una serie de actos que tienen una nota de cotidianidad y que afirman la unión entrañable entre los maestros del colegio y sus antiguos educandós. Hay una anécdota muy expresiva de los primeros tiempos del Instituto que nos cuenta cómo al saber el santo fundador que sus maestros Laínez y Salmerón habían sido enviados, por el Papa Paulo III como teólogos de Su Santidad al Concilio de Trento, Ies ordenó que antes de dar su parecer en el Concilio, se fueren al hospital y sirvieren.en él a los pobres enfermos, y enseñasen a los niños, los principios de nuestra santa fe, y después de haber echado estas raíces pasaran adelante y cumpliesen sus propósitos. (1)

La Asociación de Antiguos Alumnos del Colegio de Belén me ha honrado designándome para que diga en su nombre unas breves palabras en uno de los actos de la semana conmemorativa del cuarto centenario de la fundación de este Instituto glorioso. $Y$ vengo a cumplir un mandato de conciencia al aceptar la honrosísima designación. No pensé en lo decaído en que forzosamente ha de encontrarse mi ánimo después de tres años de labores cotidianas en un cargo oficial, 
de nombre sonoro pero de limitadísimas posibilidades, no pensé en el cansancio natural, ni en tantas ilusiones marchitas, ni en que nunca he podido sentir esa inconfundible luz interior que acompaña a todo acento de auténtica oratoria, sino que he sido simplemente, humildemente, un estudiante de por vida. Pensé tan sólo que era un deber mío levantar mi débil voz en estas fiestas del centenario y acepté con júbilo y gratitud la invitación de mi querido amigo y condiscípulo el Dr. Nicolás Sierra, presidente dignísimo de la Asociación de Antiguos Alumnos.

Más de una vez, puesto en el camino de los recuerdos, claro indicio de que hemos doblado en la vida el cabo de las Tormentas, he evocado el ambiente suave y apacible del viejo Colegio de Belén, donde discurrieron algunos años de mi infancia. Yo no puedo sustraerme en estos momentos, para mí de una honda y melancólica emoción, a ese ritmo, a ese fluir de intimas memorias. Veo en el nuevo y monumental escenario el mismo espíritu, la misma fe; la misma creadora esperanza, la misma enardecida caridad, y siento la convicción profunda de que todo podrá perderse, desvanecerse, menos la fuerza moral que rige nuestros destinos y la misteriosa luz, trémula y vacilante muchas veces, que guía nuestros impulsos interiores.

Hijo de un antiguo alumno, había de encontrarme en el Colegio de Belén desde el primer momento, en un ambiente familiar. No era necesario el recuerdo de los de mi sangre, este nexo profundo del discipulado paterno, para que encontrase en las vastas galerías, en las aulas luminosas y alegres, en los patios. de recreo, en este aprendizaje de la niñez tornadiza una resonancia de cosa que ya se había vivido una vez y que vibraba de manera misteriosa en nuestra tenue conciencia infantil. Cincuenta años había cumplido, o iba a cumplir ya el Colegio de Belén, cuando llamé a su puerta. Varias generaciones cubanas habían pasado por sus aulas. Era en 1904 una tradición creadora en la cultura cubana. Había formado muchas conciencias, había móodelado muchos caracteres, había intervenido, en fin, con las fuerzas imponderables del espíritu, en la génesis misma de nuestra nacionalidad. Nues- 
tra patria cubana comenzaba su trayectoria de nación libre. Esta institución, cincuentenaria entonces, le ofrecía el concurso inestimable de una comunidad de hombres de experiencia tres veces secular, de una comunidad de hombres afirmada en medio de las mayores adversidades, de las persecuciones más crueles, de los sacrificios personales más generosos, de los actos más heroicos, con silencioso heroísmo interior, con cotidiano, sereno e ignorado heroísmo casi siempre.

Sé que traduzco un estado de conciencia colectivo al decir estas palabras. Si voy con la necesaria brevedad a evocar algunos recuerdos personales, lo hago porque esta experiencia propia ha de reflejar la de muchos de los amigos de aquellos años, los que hoy con clara personalidad colectiva se acercan al Colegio de Belén para rendirle en esta su gran fecha histórica y de toda la cristiandad, un íntimo y silencioso homenaje.

Belén en 1904 era una institución gloriosa en la vida espiritual cubana. No me estoy refiriendo a hechos notorios en el orden científico como el de su gran observatorio y a la dinastía de sabios especialistas que han fijado leyes en la meteorología y han prestado eminentes servicios al país, ni al hecho tangible, que ninguna pedagogía libre de prejuicios discute, de la ejemplaridad de su docencia: al hablar de que en la vida de la nación representaba un signo de luz, de fuerza, de honda resonancia interior, estoy refiriéndome a su acción modeladora, constructiva, serena, del carácter de las nuevas generaciones, a la afirmación, en el duro cerco del positivismo finisecular, de los más auténticos e indiscutibles valores del espíritu. El Colegio había recogido la última conquista de la pedagogía, sus laboratorios eran modelo en su clase, su tradición de buenas humanidades, nota característica de su Ratio Studiorum, se mantenía con esplendor (en la cátedra de Literatura del Colegio, que hoy enaltece el muy querido Padre Rubinos, de vasta y selectísima cultura y un gran temperamento poético, comenzaba por aquellos años su brillantísima carrera literaria el Padre Félix González Olmedo, insigne humanista), las disciplinas históricas se profesaban con tal amplitud que la historia de Cuba y la de nuestras letras se daban en forma cíclica, cuando no habian alcanzado a entrar en los 
programas de la enseñanza oficial: esta peculiaridad característica del Colegio salvó en 1916 para Cuba la gran Biblioteca del erudito Escoto, importantísima para nuestras letras y que estaba a punto de emigrar a alguna universidad de los Estados Unidos. Quiero en este punto consagrar un recuerdo al Padre Oraá, ilustre figura de la Compañía y Rector del Colegio - inolvidable Rector-por aquellos años. Todo esto es mucho y puede considerarse decisivo en la historia de una institución. Pero son otros hechos los que punzan ahora en mis recuerdos. Más diversos en su expresión, pero de la misma jerarquía espiritual. Son sencillamente hechos de vida evangélica, y con esto ya lo he dicho todo.

Una vez, cuando nos preparábamos para la primera comunión (era algunos años antes del advenimiento del gran Papa de la Eucaristía, que llamó a los niños en su primera infancia al misterio inefable), faltó un día uno de nuestros compañeros. Era quizá el más fuerte, el más saludable de todos nosotros. Súbitamente había muerto. Lo supe cuando pasado el domingo volví del campo y oí la más tierna y conmovedora plática que he oído en mi vida. Por primera vez había tenido contacto con la muerte, conocía ese ambiente inconfundible y tremendo que rodea a la muerte. Sentía ese desgarrador acento de toda postrera despedida. Todo lo que aquel sacerdote de alma angélica iba diciendo tenía una profunda resonancia en nuestro espíritu infantil. El sacerdote era el director de nuestra Congregación y fué también el primer director espiritual que tuve. No es por esta circunstancia, sin embargo, por lo que lo veo rodeado siempre de un símbolo de bondad. Era de hablar sosegado, con una serenidad interior que le llenaba de luz la penetrante mirada. $Y$ lo que para nosotros era un suceso terrible, él, al recordar con una suave tristeza al ausente, nos hacía verlo como un suceso familiar, como el acaecimiento de todos los días. Pero al hablarnos así, al prepararnos de esta suerte, todos nos sentíamos misteriosa e inesperadamente confortados. En los días aquellos de mi niñez, al sentir el primer contacto con la muerte, había sentido también la inconfundible luz de lo sobrenatural. i Qué valor espiritual enorme en la conciencia infantil el de este sentido de la perdurabilidad de la vida! 
Aquel sacerdote ejemplar, que dirigió durante-muchos años la Congregación de San Estanislao de Kostka, fué el P. Miguel Santiesteban, cuya santa memoria me acompaña siempre y a la que dedico estas férvidas palabras de reconocimiento."

En nuestra segunda división había, como ocurre siempre, el alumno que mantenía durante todo el año su grado de excelencia. Tenían todos o casi todos los premios de las varias asignaturas que forman la enseñanza preparatoria para el ingreso en el bachillerato. Ni una sola vez había dejado el primer lugar de las periódicas distribuciones de premios. En los actos solemnes, con aquel uniforme tan poco deportivo que usábamos por 1904, con la corbata de lazo, con el cuello de pajarita con sus agresivas puntas, con aquel chaleco blanco que crujía y rebrillaba con el almidón, todos parecíamos iguales en el atuendo. Pero cuando íbamos con nuestro traje de diario, comprendiamos que aquel líder de los mejores estudiantes, a pesar de su pulcritud, revelaba en ciertos detalles la dura vida de su casa, el batallar constante y afanoso con la siempre apocada fortuna. Aquel compañero era para todos nosotros un ejemplo. Representaba la voluntad férrea, el ansia de superación, la actitud firme ante la vida. Todo lo obtenía del Colegio: elementos para sus estudios, recompensas para su aplicación, estímulos para su conducta. En él se cumplía una de las grandes funciones sociales del Colegio. Esa gran función de la justicia, que exalta el mérito, que sabe descubrirlo, aun en la más desvalida de las criaturas. Aquel hijo de sus propias obras llegó a ser en nuestra mente infantil un símbolo. A la distancia veo lo que pudo influir en los rumbos de mi vida. Desde luego no es necesario que diga que todo esto tocaba en las puras esencias de la democracia. Para todos nosotros, muchachos de diez a trece años, era aquello una lección de vida.

Pero no sólo debe reconocerse, estimularse, el esfuerzo que corona el éxito, sino que la simple voluntad, el propósito firme y denodado merecen también el saludable estímulo. De este sentido de justicia, matizado quizá de misericordia, tuve yo una experiencia directa, $y$, después de tanto tiempo, no alcan- 
zo a ver lo sucedido como un infortunio. Yo tenía tantas aficiones a la declamación como inhabilidad para su ejercicio. Tenazmente habíal logrado ciertas cualidades en la dicción. Mas el gesto era siempre torpísimo, sin expresión alguna. Pero mi tenacidad, mi esfuerzo, me valieron uno de los primey̧os lugares en el programa literario de una de las fiestas del Colegio. Yo no sé lo que pasó por mí cuando no me vi frente al buen maestro sino ante una concurrencia nutridísima de familias de alumnos y de todo el Colegio. Recuerdo que la poesía tenía este título: "Una pregunta a María Inmaculada". Salí de aquello con el ánimo de nunca más reincidir. Uno de mis compañeros no vaciló en decirme su juicio poco generoso: "Has estado fatal". Recuerdo con precisión sus palabras, al cabo de tantos años. Como también que en aquella misma fiesta obtuvo uno de sus primeros triunfos de recitador sonoro, vibrante, un amigo inolvidable, poeta de raíz, poeta en medio de su prodigalidad sin tasa, y aun de sus concesiones constantes a una literatura circunstancial y de tono menor. Aquí, en este Colegio de Belén, se formó su espíritu lírico, aquí fué enriqueciendo sus cualidades temperamentales, aquí encontró en el P. Olmedo el más generoso de los maestros. Gozó de fama dilatada : escribió más de veinte libros, cultivó el teatro, llegó a conocer todos los halagos y todos los peligros de la popularidad. Murió de súbito en lo mejor de su juventud. Un olvido injusto ha ido envolviendo. a su nombre. Deber es de los que fuimos sus amigos, de los que conocimos los ricos dones de aquella alma privilegiada, de los que presenciamos en la niñez sus triunfos iniciales, ir rescatándolo de esta niebla que envuelve su claro nombre lírico. Porque, sin este nombre, el de Gustavo Sánchez Galárraga, no podrá escribirse la historia de la poesía cubana en el período que va de 1910 a 1934 : los veinte y cuatro años largos que vivió el poeta para su arte generoso.

Con deliberado propósito he rehuído en esta evocación de pequeños y grandes recuerdos la forma histórica, vocación esencial de mi vida. Solamente quiero subrayar un hecho, que llega a mi memoria con una honda significación. Fué aquí donde sentí por primera vez, en aquellos mis doce años, esa profunda pasión de mi humilde vida estudiosa, la vocación 
por la historia. Fué el Padre Bonifacio, maestro de varias generaciones, tan querido de todos los que pasamos por su cátedra, quien una, vez, al aproximarse uno de los ejercicios de oposición a premios, puso en mis manos un libro de Historia 'de Cuba, dístinto al epítome que teníamos en clase. La explanación de hechos que aparecían tan abreviados en nuestro pequeño-manual, tuvo una profunda influencia en mis años infantiles. Sentí que aquello me apasionaba, me llenaba de un interés hasta entonces desconocido. Nunca lo he podido olvidar y es uno de los muchos nexos de gratitud que me ligan con el Colegio de Belén.

1904-1940.-Treinta y seis años que suponen un cambio radical, enorme, en las perspectivas del mundo. Luchaban en el Oriente Rusia y el Japón, cuando pasé aquellos años infantilès en el viejo Belén. En los tradicionales desafíos de la clase, los nombres de esos dos imperios modernos habían sustituído a los de Roma y Cartago. Hoy no sería posible una alusión de ese tipo al pavoroso conflicto que vive el mundo.

En 1540 la Compañía de Jesús desempeña un papel fundamental en la tremenda conmoción social que significó para el hombre la Reforma. El vicario de Cristo tuvo en los compañeros de Jesús la noble y generosa vanguardia que le permitió vencer en la prueba decisiva. En 1940 la guerra totalitaria que conmueve a la humanidad, supone ciertamente para el Jefe de la Iglesia una prueba no menos decisiva y amarga que la que fué la lucha de la Reforma para el gran Papa que promulgó la bula de Constitución de la Compañía y que afirmó la dignidad del hombre fallando la vieja disputa entre los aristotélicos que seguían a Sepúlveda y los lascasistas que se mantenían fieles al gran Apóstol Fray Bartolomé, reconociendo que los indios, habitantes de las tierras recién descubiertas, tenían también ánimas racionales.

No parece un azar de la historia el hecho de que el Papa que afirma la dignidad íntegra del hombre sea el mismo-que suscriba el acta de nacimiento de la Compañía de Jesús." Y no debe ser tampoco una sola ilusión consoladora lo que en tantas conciencias cristianas hace sentir el próximo papel decisivo 
de los compañeros de Jesús en esta lucha de magnitud cósmica. $Y$.el clamor universal por la paz, por una paz justa, llega a su trémolo más angustiado, en estos días del cuarto centenario. "Cuando aparece la angustia es que vuelve la cristiandad", decía el Cardenal Peguy. La paz por la que clamaba supone esta vuelta total a la vida cristiana. Supone la vigencia absoluta del gran principio de universalidad que proclamó San Pablo, en su Epístola a los Gálatas: "Y ya no hay distinción de judío ni griego, ni de siervo ni libre, ni de hombre ni mujer. Porque todos vosotros sois una cosa en Jesucristo".

En esta labor ingente jcuántos trabajos esperan a la Compañía de Jesús, vanguardia del catolicismo, es decir, vanguardia de la universalidad!

\section{J. M. Chacón y Calvo, La Habana.}

(1).-Discurso leído en la fiesta de los antiguos alumnos del Colegio de Belén (La Habana) para conmemorar el cuarto centenario de la fundación de la Compañía de Jesús.

(2).-Rivadeneira: Vida de San Ignacio. 